\title{
Production of humic acid from pineapple leaf residue
}

\begin{abstract}
The study was carried out with the following objectives: (i) to quantify the amount of humic acid (HA) that could be extracted from composted pineapple leaf residue using potassium hydroxide $(\mathrm{KOH})$ produced from pineapple leaf residue, and (ii) to compare the elemental composition, functional groups, and spectral characteristics of HA extracted from composted pineapple leaf using $0.1 \mathrm{M} \mathrm{KOH}$ from pineapple leaf and that of analytical grade $(0.1 \mathrm{M}$ $\mathrm{KOH}$ ). The $0.1 \mathrm{M} \mathrm{KOH}$ from pineapple leaf residue extracted $20 \%$ HA from composted pineapple leaf residue while that of the analytical grade $(0.1 \mathrm{M} \mathrm{KOH})$ extracted $30 \%$. The elemental composition $(\mathrm{C}, \mathrm{H}, \mathrm{N}, \mathrm{O}$, and $\mathrm{S}$ ), functional groups (carboxylic, phenolic $\mathrm{OH}$, and total acidity), and spectral characteristics of the HA extracted using the 2 extractants were generally similar. Potassium hydroxide from pineapple leaves can be used to extract some reasonable amount of HA without appreciably altering the elemental and functional groups constitution as well as the spectral characteristics. The potential of using $\mathrm{KOH}$ from pineapple leaf residue in HA studies appears promising. (C) 2003 by The Haworth Press, Inc. All rights reserved
\end{abstract}

Keyword: Humic acids; KOH; Pineapple leaves; Potassium hydroxide 